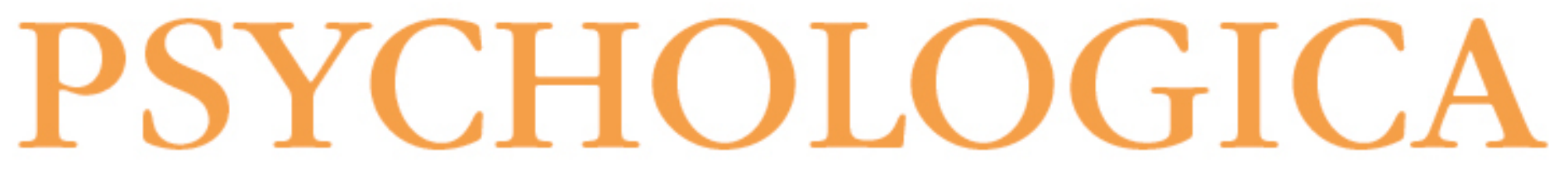

Minnesota Satisfaction Questionnaire - short form: estudo de adaptação e validação para a população portuguesa

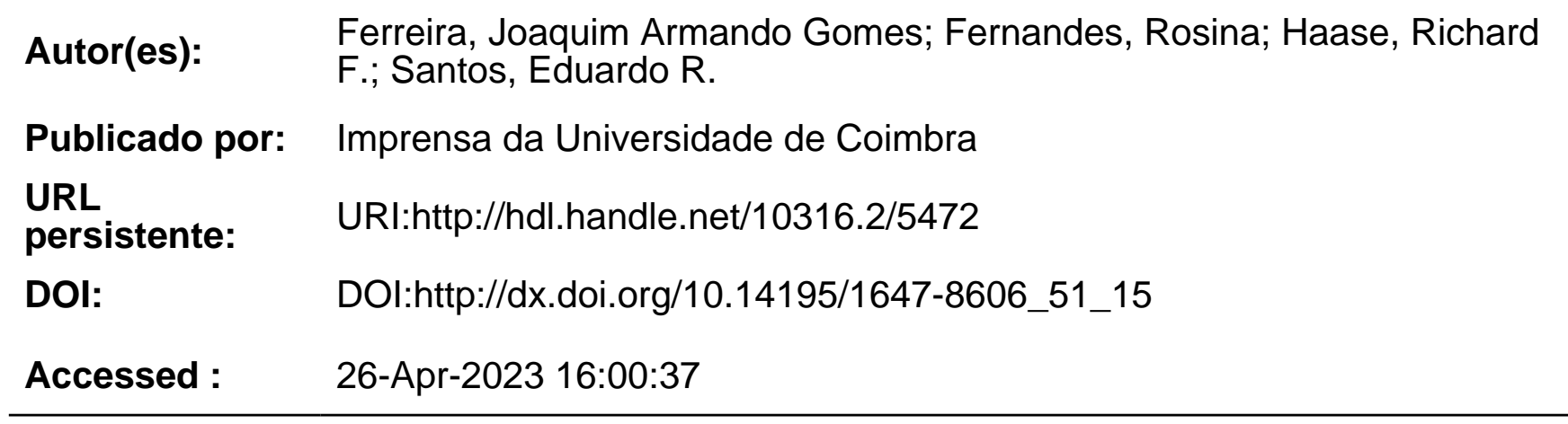

A navegação consulta e descarregamento dos títulos inseridos nas Bibliotecas Digitais UC Digitalis, UC Pombalina e UC Impactum, pressupõem a aceitação plena e sem reservas dos Termos e Condições de Uso destas Bibliotecas Digitais, disponíveis em https://digitalis.uc.pt/pt-pt/termos.

Conforme exposto nos referidos Termos e Condições de Uso, o descarregamento de títulos de acesso restrito requer uma licença válida de autorização devendo o utilizador aceder ao(s) documento(s) a partir de um endereço de IP da instituição detentora da supramencionada licença.

Ao utilizador é apenas permitido o descarregamento para uso pessoal, pelo que o emprego do(s) título(s) descarregado(s) para outro fim, designadamente comercial, carece de autorização do respetivo autor ou editor da obra.

Na medida em que todas as obras da UC Digitalis se encontram protegidas pelo Código do Direito de Autor e Direitos Conexos e demais legislação aplicável, toda a cópia, parcial ou total, deste documento, nos casos em que é legalmente admitida, deverá conter ou fazer-se acompanhar por este aviso.

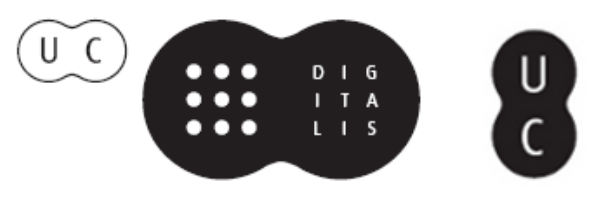


NÚMERO 51

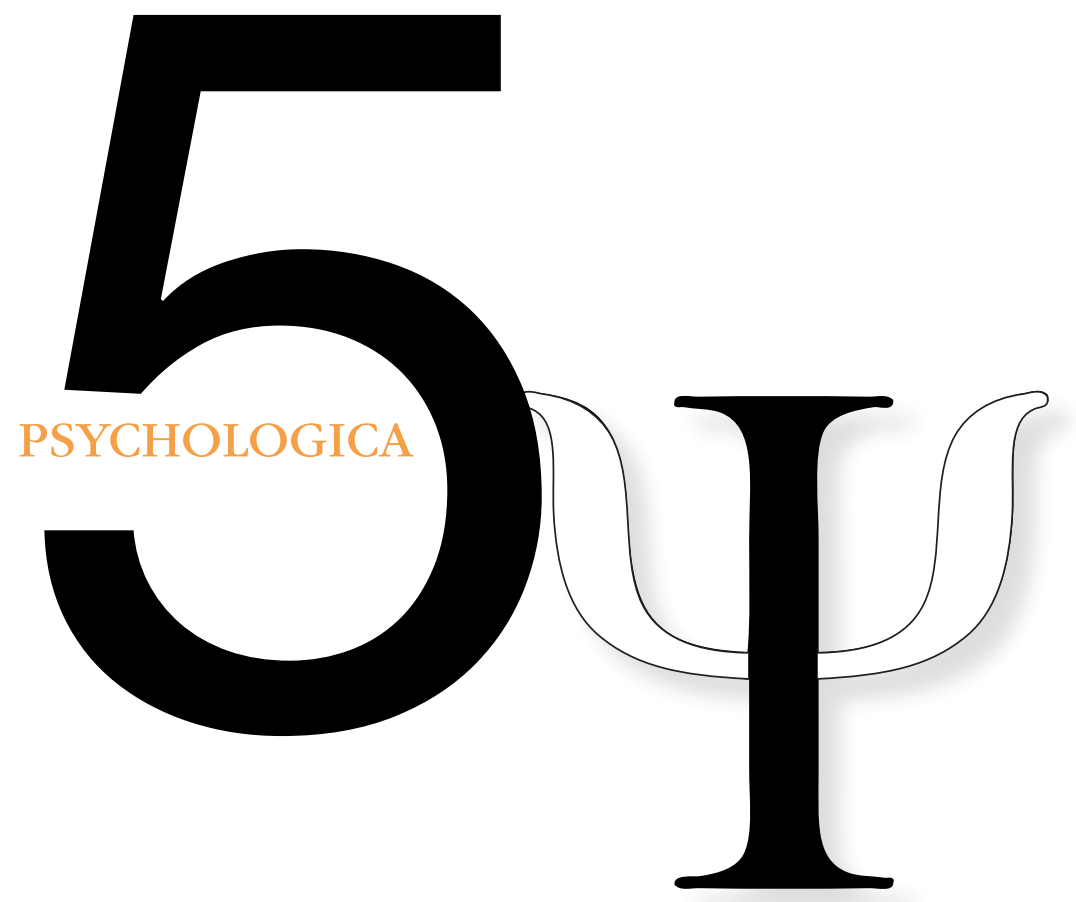

IMPRENSA DA UNIVERSIDADE DE COIMBRA

FACULDADE DE PSICOLOGIA E DE CIÊNCIAS DA EDUCAÇÃO DA UNIVERSIDADE DE COIMBRA 


\section{Minnesota Satisfaction Questionnaire - Short Form: estudo de adaptação e validação para a população portuguesa}

Joaquim Armando Gomes Ferreira', Rosina Fernandes², Richard F. Haase ${ }^{3}$ \& Eduardo R. Santos'

A satisfação com o trabalho é a dimensão mais estudada na Psicologia Organizacional (Spector, 1997), contudo, investigações recentes sobre os seus instrumentos de avaliação são pouco frequentes (Saane, Sluiter, Verbeek, \& Frings-Dresen, 2003). Neste sentido, pretende-se contribuir para o estudo das características psicométricas de um instrumento amplamente utilizado neste âmbito, o Minnesota Satisfaction Questionnaire (MSQ) - Short Form (Weiss, Dawis, England, \& Lofquist, 1967), adaptando-o à população portuguesa.

Os resultados obtidos evidenciam qualidades psicométricas adequadas, com um valor elevado de consistência interna, coeficientes de estabilidade adequados (teste-reteste) e uma ajustada validade convergente (resultante da correlação com o Cuestionario de Satisfaccion S2O/23 de Meliá e Peiró, 1989). A análise factorial exploratória revela uma estrutura que aponta para a existência de dois factores de satisfação com o trabalho.

A discussão dos resultados salienta a necessidade de mais estudos sobre esta temática, sendo levantadas algumas pistas para futuras investigações.

PALAVRAS-CHAVE: Minnesota Satisfaction Questionnaire - Short Form; Análise Psicométrica, Validade Convergente e de Constructo; Satisfação com o Trabalho.

\section{Introdução}

A satisfação com o trabalho é a variável mais estudada em investigação sobre o comportamento organizacional (Spector, 1997). Este facto prende-se com questões de ordem humanística, tendo em conta que a satisfação com o trabalho está relacionada com o bem-estar subjectivo dos trabalhadores (Judge \& Hulin, 1993

\footnotetext{
1 Faculdade de Psicologia e de Ciências da Educação da Universidade de Coimbra.

2 Escola Superior de Educação do Instituto Politécnico de Viseu.

3 State University of New York at Albany, EUA.
} 
cit in Hirschfeld, 2000), e com a satisfação da vida em geral (Judge \& Watanabe, 1993 cit in Hirschfeld, 2000), mas negativamente associada à fadiga e mortalidade por doença cardíaca (Locke, 1976, cit in Saane, Sluiter, Verbeek, \& Frings -Dresen, 2003). Acrescente-se, que a longevidade está positivamente associada à satisfação com o trabalho (Locke, 1976, cit in Saane et al. 2003).

Numa perspectiva utilitarista para a própria organização, a satisfação dos seus trabalhadores revela-se fundamental, na medida em que conduz a comportamentos que podem afectar os seus resultados de produção (Spector, 1997). Segundo DeNeve e Cooper (1998, cit in Simões, Ferreira, Lima, Pinheiro, Vieira, Matos, \& Oliveira, $2000,251)$ as pessoas que tendem a sentir-se mais satisfeitas com a vida "fixam objectivos mais elevados e tendem a obter melhores resultados, no contexto do trabalho". De acordo com Saane et al. (2003), a satisfação com o trabalho pode funcionar como um factor de prevenção das condições que conduzem a uma elevada taxa de stress ocupacional e consequente possivel abandono laboral.

A satisfação com o trabalho constitui-se, assim, como uma dimensão com dupla influência. Isto é, repercute-se no trabalhador e, ao mesmo tempo, reflecte-se no funcionamento das organizações. Consequentemente, a avaliação da satisfação com o trabalho torna-se fundamental quer para o trabalhador, quer para a própria organização (Saane et al., 2003). Na perspectiva dos mesmos autores, esta é uma prática comum em organizações que se preocupam com o bem-estar dos seus trabalhadores, seja por razões humanísticas ou por questões de eficácia e eficiência organizacional.

Ao avaliar a satisfação com o trabalho, a organização pode detectar a necessidade de implementar medidas que melhorem a qualidade de vida de trabalho e, inevitavelmente, potenciem os seus resultados produtivos (Saane et al., 2003). Um trabalhador satisfeito no seu local de trabalho preocupa-se mais com a qualidade das tarefas que desenvolve, valoriza o cliente, compromete-se mais com a organização, sendo, em última instância, o seu trabalho mais produtivo. Com efeito, uma organização com trabalhadores satisfeitos melhora a qualidade do seu produto, aumenta a satisfação e lealdade do seu cliente, reduz os custos com o abandono laboral e necessário processo de recrutamento e formação de novos trabalhadores, previsivelmente, apresenta maior produtividade (Ngo, 2009). É nesta transacção recíproca que a satisfação com o trabalho pode actuar como um factor mediador do sucesso individual e organizacional.

Autores como Spector (1997) e Stone-Romero (1994) (cit in Hirschfeld, 2000) referem que, para uma avaliação útil da satisfação com o trabalho, os instrumentos devem ser precisos, isto é, devem apresentar características psicométricas adequadas. Saliente-se, o Minnesota Satisfaction Questionnaire (MSQ) - Short Form (Weiss, Dawis, England, \& Lofquist, 1967), cujas qualidades métricas continuam a merecer 
a atenção dos investigadores nesta área em estudos mais recentes (como, por exemplo, no estudo de Hirschfeld, 2000).

Deste modo, a importância da investigação no âmbito das características psicométricas dos instrumentos de avaliação da satisfação com o trabalho revela-se fundamental, não só para a compreensão do conceito, mas, sobretudo, com o objectivo de permitir a promoção das mudanças necessárias ao aumento da satisfação com o trabalho e decorrentes repercussões ao nivel do trabalhador e da organização.

\section{Satisfação com o trabalho}

\subsection{Definição e caracterização do conceito}

De acordo com Saane et al. (2003), a satisfação com o trabalho é um conceito que se constrói numa dimensão espácio-temporal específica. Apesar deste relativismo conceptual, na literatura sobre satisfação com o trabalho há um consenso quanto à sua definição. Para Spector (1997, cit in Sebera, 2005, 10) a satisfação com o trabalho refere-se "ao que as pessoas sentem sobre o seu trabalho e as suas diferentes dimensões", constituindo-se como uma atitude geral em relação ao trabalho, que envolve uma avaliação cognitiva e afectiva (Ngo, 2009). De uma forma simplificada, representa o quanto as pessoas gostam do seu trabalho (Spector, 1997, cit in Hirschfeld, 2000).

É visível que algumas pessoas gostam do seu trabalho e consideram-no uma parte central da sua vida, enquanto que outras não gostam e trabalham "porque tem que ser". O estudo das causas e consequências associadas a estas questões constitui-se como um dos focos centrais da psicologia organizacional há várias décadas (Ahmadi \& Alireza, 2007).

\subsection{Perspectiva histórica: concepções teóricas e estudos empíricos}

No passado, o conceito de satisfação com o trabalho era compreendido numa perspectiva de resposta a necessidades, isto é, se o trabalho permitia a satisfação das necessidades físicas ou psicológicas do trabalhador (Porter, 1962; Wolf, 1960 cit in Spector, 1997). Uma das perspectivas teóricas que se enquadra nesta concepção é a de Herzberg (considerado por muitos como um pioneiro na teoria da motivação), que, no final dos anos 50, entrevistou um grupo de trabalhadores para compreender o que os fazia sentir-se satisfeitos ou insatisfeitos com o trabalho (Herzberg, Mausner, \& Snyderman, 1959).

Com base neste estudo, o autor desenvolveu a sua teoria sobre satisfação com o trabalho, assente em duas dimensões: a motivação e a "higiene". Os factores 
associados à primeira dimensão (realização, reconhecimento, o trabalho per si, responsabilidade e progressão) promovem a satisfação com o trabalho e, inevitavelmente, melhoram a produtividade. Quanto à segunda dimensão (que inclui factores externos, como por exemplo, políticas da instituição, supervisão, salário, relações interpessoais e condições de trabalho), apesar de não motivar directamente o trabalhador, minimiza a sua insatisfação (Herzberg, Mausner, \& Snyderman, 1959).

Actualmente, a investigação tem vindo a valorizar os processos cognitivos na análise da satisfação com o trabalho, colocando, de parte, a ênfase na satisfação de necessidades internas (Spector, 1997).

Embora seja possivel verificar a existência de outras teorias de referência na história deste conceito, esta breve retrospectiva incidirá, unicamente, nas que Saane et al. (2003) referem no seu trabalho: o modelo de características do trabalho (Hackman \& Oldham, 1976); a teoria de dois factores (Thierry, 1998); a teoria de valor (Locke, 1976); a teoria de discrepância (Lawler \& Hall, 1970); a teoria de processamento de informação social (Pollock \& Whitbred, 2000); e a teoria de ocorrência situacional (Quarstein, McAfee, \& Glassman, 1992).

De acordo com os autores (Saane et al., 2003), apenas o modelo de Hackman e Oldham (1976) descreve de forma explícita os factores relevantes para a compreensão da satisfação com o trabalho, nomeadamente a variedade de competências, a identificação da tarefa, o significado da tarefa, a autonomia e o feedback.

$\mathrm{Na}$ actualidade, vários estudos têm procurado explorar quais os factores associados à satisfação com o trabalho. Saane et al. (2003) apresentam uma categorização de factores associados à satisfação com o trabalho com onze domínios: conteúdo do trabalho (variedade de competências, complexidade ou desafio do trabalho exercido, definição de papéis e rotina); autonomia (responsabilidade individual pelo trabalho e controlo sobre as decisões tomadas no exercício das funções); desenvolvimento pessoal e profissional; recompensas (salário e outros benefícios financeiros para o trabalhador); promoção (possibilidade de progressão na carreira ou na categoria laboral); supervisão (apoio e reconhecimento demonstrados pelo supervisor e tratamento com justiça); comunicação (oportunidades de aconselhamento efeedback); relações profissionais com os colegas; significação do trabalho; peso do trabalho (percepção subjectiva da pressão temporal, tédio, problemas sociais, conflitos interpessoais e stress); e exigências do trabalho (trabalho extraordinário involuntário, complexidade estrutural, insegurança na situação laboral e compromisso emocional). Os autores salientam, também, em estudos mais recentes, a importância de considerar, o equilíbrio entre trabalho e vida privada como uma parte integrante da satisfação com o trabalho. 
Ngo (2009) aponta vários aspectos associados à satisfação com o trabalho: trabalho interessante e apreciado, segurança/estabilidade, bom salário e outros incentivos (férias pagas pela organização, seguros de acidente ou saúde, transporte), possibilidade de promoção e desenvolvimento, boas condições de trabalho, lealdade dos trabalhadores, políticas organizacionais adequadas, ajuda aos problemas dos trabalhadores, flexibilidade temporal, entre outros. Estes factores podem ser sistematizados num modelo de cinco elementos: (1) compensação e benefícios; (2) promoção e formação; (3) tarefas de trabalho; (4) colegas de trabalho; e (5) supervisão.

No entanto, independentemente da forma como é conceptualizada, a satisfação com o trabalho tem vindo a ser cada vez mais explorada, com implicações práticas para a vida da organização e do trabalhador.

Ngo (2009) sugere, ainda, duas estratégias globais de intervenção para manter a satisfação do trabalhador: frequência da avaliação do grau de satisfação dos trabalhadores (deve ser pelo menos de 3 em 3 meses, ou de 6 em 6 meses, mas por vezes é necessário realizá-la com mais frequência) e implementação de feedback regular.

Numa perspectiva mais específica, o mesmo autor sugere dez "boas práticas" organizacionais para melhorar a satisfação com o trabalho. A primeira refere-se ao desenvolvimento da organização, isto é, se a organização partilhar com os seus trabalhadores a sua missão, visão global e objectivos, e procurar conhecer também as opiniões dos seus trabalhadores, estes sentir-se-ão mais envolvidos e poderão utilizar, da melhor maneira, as suas potencialidades promovendo a evolução da organização. Este aspecto pode ficar garantido logo na fase da contratação, na medida em que a organização deve procurar contratar os trabalhadores adequados, definindo e comunicando claramente, num momento inicial, as expectativas sobre o trabalhador (Ngo, 2009).

O autor salienta, também, a importância da rotação nas funções do trabalhador de modo a permitir o seu contacto com uma maior variedade de tarefas e o consequente enriquecimento do seu conhecimento. $O$ terceiro aspecto refere-se à adequação das recompensas e benefícios para o trabalhador. Este factor relaciona-se com a quarta linha de actuação, centrada na implementação de um programa de avaliação justo, e aplicado de forma a encorajar o bom desempenho do trabalhador. Deste modo, a implementação de programas de formação e a existência de promoções, possibilitando a progressão na carreira (Ngo, 2009), deve ser tido em consideração.

Um dos factores que mais influencia a satisfação dos trabalhadores é a sua relação com os supervisores. Ngo (2009) salienta a importância da direcção apoiar os tra- 
balhadores e tratá-los de forma justa. Da mesma forma, devem ser promovidas as relações entre os colegas de trabalho, potenciando o trabalho em equipa através da construção de canais de comunicação ajustados (Ngo, 2009).

Para além da dimensão processual (centrada nas interacções), a organização caracteriza-se pela sua dimensão mais estrutural. Assim, não deve negligenciar as condições gerais de trabalho, garantindo a segurança, saúde e higiene no trabalho. Finalmente, é realçada a importância do departamento de recursos humanos no implementar programas de monitorização e na melhoria da satisfação dos trabalhadores (Ngo, 2009).

No seu conjunto, estas linhas actuais de investigação estão intimamente relacionadas com a temática da avaliação da satisfação com o trabalho, com vista à melhoria da qualidade de vida do trabalhador e da organização.

\section{Avaliação da satisfação com o trabalho}

A avaliação da satisfação com o trabalho constitui-se como o primeiro passo para a acção, com vista à promoção de mudanças no desenvolvimento teórico e nas práticas em contexto.

A satisfação com o trabalho pode ser medida num continuum entre a insatisfação (regularmente associada ao stress e burnout), passando por um estado neutro, até à satisfação (Levinson, 1998). Esta medição pode ser efectuada através da observação ou do inquérito (por entrevista ou questionário), directa ou indirectamente, junto dos trabalhadores.

Como exemplo, Glick, Junkins e Gupta (1986, cit in Spector, 1997) procederam à observação (procurando aceder de forma indirecta ao grau de satisfação com o trabalho) dos trabalhadores no desempenho das suas funções durante 2 horas. Os autores encontraram uma correlação moderada entre a satisfação com o trabalho resultante da observação e aquela reportada pelos trabalhadores. Também Spector, Dwyer e Jex (1988, cit in Spector, 1997) procuraram avaliar de forma indirecta a satisfação com o trabalho questionando os supervisores, tendo obtido uma correlação moderada com os sentimentos referidos pelos trabalhadores.

Contudo, Spector (1997) defende que o recurso a outras fontes não é equivalente ao questionar directo dos trabalhadores. Neste acesso directo à satisfação com o trabalho, é possível utilizar a entrevista (com a sua inquestionável riqueza de informação passivel de ser recolhida), no entanto, a maioria dos estudos nesta área utiliza o questionário cuja aplicação se revela mais rápida e menos dispendiosa, permitindo uma quantificação mais fácil das respostas (Spector, 1997). 
Alguns dos instrumentos de avaliação da satisfação com o trabalho englobam várias dimensões associadas a este conceito. Um dos mais utilizados na investigação organizacional, de acordo com Saane et al. (2003), é o Job in General Scale (JIG) de Ironson, Smith, Brannick, Gibson e Paul (1989) que está incluido no Job Descriptive Index (JDI) de Smith et al. (1989).

O Minnesota Satisfaction Questionnaire - MSQ (Weiss, Dawis, England \& Lofquist, 1967) também se enquadra neste conjunto de instrumentos permitindo aceder a 20 dimensões associadas à satisfação com o trabalho. A versão reduzida do S4/82 (Meliá, Peiró \& Calatayud, 1986), isto é, o Cuestionario de Satisfaccion S2O/23, avalia a satisfação com o trabalho segundo um modelo teórico que inclui várias dimensões (Carlotto \& Câmara, 2008).

Outros instrumentos, por sua vez, centram-se apenas numa dimensão associada à satisfação com o trabalho (como por exemplo, o Andrew and Withey Job Satisfaction Questionnaire de Rentsch \& Steel, 1992) como salientam Saane et al. (2003).

Há, ainda, instrumentos que podem ser utilizados em vários contextos de trabalho. Saliente-se o Job Satisfaction Survey (JSS, Spector, 1985), que apesar de ter sido desenvolvido originalmente para o sector do serviço social, pode (de acordo com o autor) ser utilizado noutros sectores laborais (Saane et al., 2003).

Por fim, existem instrumentos construidos especificamente para determinadas ocupações profissionais (Saane et al., 2003): Emergency Physician Job Satisfaction Scale (EPJS) desenvolvido para avaliar a satisfação com o trabalho de médicos em departamentos de emergência por Lloyd, Streiner, Hahn e Shannon (1994); Nurse Satisfaction Scale (NSS), um instrumento desenvolvido por Ngo (1993) para avaliar a satisfação entre enfermeiros; McCloskey/Mueller Satisfaction Scale (MMSS) criado por Mueller e McCloskey (1990) também para ser aplicado a enfermeiros mas em contexto hospitalar; o Measure of Job Satisfaction (MJS) de Traynor e Wade (1993), para o sector da enfermagem comunitária; e o Teacher Job Satisfaction Questionnaire (TJSO) de Lester (1982; adaptação portuguesa de Seco, 2000) para avaliar a satisfação profissional dos professores.

A investigação sobre satisfação com o trabalho tem sido realizada há várias décadas e diversos tipos de instrumentos têm sido desenvolvidos, contudo, são raras as investigações sobre a adequação das propriedades psicométricas destes instrumentos (Saane et al., 2003). A importância destes estudos manifesta-se nas suas implicações práticas para a melhoria da qualidade de vida laboral, e, simultaneamente, nas repercussões em termos teóricos na compreensão conceptual da satisfação com o trabalho.

Recentemente, algumas investigações neste âmbito têm salientado a importância de incluir outras dimensões associadas à satisfação com o trabalho que, tradi- 
cionalmente, não eram valorizadas. A dimensão da significação do trabalho, para o trabalhador, é uma componente fundamental da satisfação com o trabalho, que embora tenha sido explorada por Hackman e Oldham (1976) no seu modelo teórico, raramente é incluída nos instrumentos de avaliação da satisfação com o trabalho (Saane et al., 2003). Também são poucos os instrumentos que incluem a dimensão do desenvolvimento pessoal e profissional através do trabalho. Este é um factor que alguns trabalhadores e organizações têm vindo a valorizar mais recentemente e que na perspectiva de Saane et al. (2003), deve ser incluído nos instrumentos mais recentes.

\subsection{Um instrumento de referência: O Minnesota Satisfaction Question- naire (MSO)}

Como já foi referido, a satisfação com o trabalho é determinada por um grande conjunto de factores. Um dos instrumentos de referência nesta área, que procura incluir inúmeras dimensões associadas à satisfação com o trabalho, é o Minnesota Satisfaction Questionnaire - (MSO) de Weiss, Dawis, England e Lofquist (1967). Este instrumento fornece informação mais específica sobre os factores associados à satisfação com o trabalho do que a maioria das medidas gerais (Weiss, Dawis, England, \& Lofquist, 1967).

O MSO resultou dos estudos realizados no âmbito do Work Adjustment Project na University of Minnesota (Jewell, Beavers, Kirby, \& Flowers, 2001), cuja teoria subjacente, assenta no pressuposto de que o ajustamento laboral depende da correspondência entre as capacidades individuais e os reforços existentes no ambiente de trabalho (Weiss, Dawis, England, \& Lofquist, 1967). É um instrumento de auto-preenchimento acessivel a indivíduos de todos os níveis de escolaridade, que pode ser administrado em grupo ou individualmente, requerendo cerca de 15 a 20 minutos para ser aplicado (Weiss, Dawis, England, \& Lofquist, 1967). O MSO inclui 100 itens que permitem avaliar 20 dimensões (cada uma com 5 questões) da satisfação com o trabalho (Ahmadi \& Alireza, 2007).

As dimensões incluídas no MSO referem-se a aspectos como: actividade (ser capaz de se manter ocupado durante todo o tempo); independência (possibilidade de trabalhar de modo independente no seu cargo); variedade (possibilidade de fazer coisas diferentes de tempos a tempos); estatuto social (oportunidade de "ser alguém na vida"); valores morais (possibilidade de fazer coisas que não vão contra a consciência/valores); segurança e estabilidade que o emprego fornece; serviço social (possibilidade de ajudar outras pessoas); autoridade (possibilidade de dizer às pessoas o que fazer); utilização das capacidades (fazer algo em que faça uso das competências pessoais); responsabilidade (oportunidade para tomar 
decisões por si próprio); criatividade (possibilidade de utilizar os próprios métodos para a realização do trabalho); e realização pessoal que se obtém com o trabalho (Weiss, Dawis, England, \& Lofquist, 1977).

Também inclui aspectos como: progressão profissional; políticas da instituição (forma como são implementadas); compensação (pagamento pela quantidade de trabalho realizado); supervisão-relações humanas (modo como o supervisor lida com subordinados - componente interpessoal); supervisão-técnica (competência do supervisor na tomada de decisões - componente de competência técnica); e reconhecimento por fazer um bom trabalho (Weiss, Dawis, England, \& Lofquist, 1977). Finalmente, explora a dimensão dos colegas de trabalho (modo como se relacionam entre si) e as condições gerais de trabalho (Weiss, Dawis, England, \& Lofquist, 1977).

Existem 3 versões do instrumento: duas em formato completo (1977 e 1967) e uma forma reduzida (Ngo, 2009). De acordo com os autores, aconselha-se a utilização do instrumento na sua versão mais longa (a não ser quanto é impraticável, já que aplicação da versão breve demora apenas 5 minutos) pois fornece muito mais informação.

A versão reduzida do $\mathrm{MSO}$ inclui apenas 20 itens retirados da versão original do instrumento, que melhor representam as 20 dimensões avaliadas pelo questionário na sua versão completa (Ahmadi \& Alireza, 2007). Cada item é respondido pelo trabalhador numa escala de tipo Likert com 5 alternativas de resposta, oscilando entre muito insatisfeito (pontuação 1) e muito satisfeito (pontuação 5). A pontuação total do MSO - versão reduzida pode assim variar entre 20 e 100 (Jewell, Beavers, Kirby, \& Flowers, 2001).

A versão reduzida do instrumento é constituida por itens que representam uma faceta intrínseca (MSOL) ou extrínseca (MSOE) da situação laboral, de acordo com a análise factorial realizada pelos autores. A primeira refere-se ao que as pessoas sentem acerca da natureza das tarefas do trabalho (Spector, 1997), e a segunda ao que sentem em relação a aspectos do trabalho que são externos às tarefas ou ao trabalho em si, como por exemplo, o salário (Sebera, 2005). Existem ainda itens que não se enquadram nas duas subescalas referidas, sendo considerados itens gerais de satisfação com o trabalho (Sebera, 2005). A subescala de satisfação intrínseca envolve 12 itens $(1,2,3,4,7,8,9,10,11,15,16$ e 20) com pontuações totais que podem variar entre 12 e 60 . Por sua vez, a subescala de satisfação extrínseca envolve 6 itens $(5,6,12,13,14$ e 19) cuja pontuação total se situa entre 6 e 30. Os itens 17 e 18 são considerados gerais (Jewell, Beavers, Kirby, \& Flowers, 2001).

Weiss et al. (1967) encontraram coeficientes de fidelidade para a MSOI de .86 e para os respectivos itens, valores entre .77 e .82. Relativamente à MSOQE, apontaram 
um coeficiente de fidelidade de .80 , variando entre .84 e .91 no que concerne aos itens. Para a escala total, os autores reportaram um coeficiente de fidelidade de .87 (variando para os itens entre .74 e .91). Estes coeficientes revelam uma consistência interna bastante satisfatória da escala, confirmada pela forte correlação teste-reteste dos resultados gerais da escala (coeficiente de .89 no período de uma semana, e .70 no intervalo de um ano).

Também Robert, Young e Kelly (2006) verificaram a elevada fidelidade do instrumento, revelando coeficientes de consistência interna para a escala geral, MSOI e MSOE de .82, .88 e .80, respectivamente. No mesmo sentido, Levinson (1998) aponta uma consistência interna entre .84 e .91 para a MSOl; entre .77 e .82 para a MSOE; e entre .87 e .92 para o resultado geral. Verificou, ainda, uma correlação teste-reteste para o resultado total de .89 (intervalo de uma semana) e .70 (intervalo de um ano).

Existe alguma evidência empírica que suporta a existência de validade divergente das duas componentes da satisfação com o trabalho (intrínseca e extrínseca) nas suas relações com outras variáveis relevantes. Brown (1996), na sua meta-análise, encontrou resultados que sugerem que a satisfação intrínseca com o trabalho, comparativamente à satisfação extrínseca, está mais fortemente relacionada com o envolvimento no trabalho. Também os resultados de Moorman (1993) indicam que a satisfação intrínseca com o trabalho tem uma base afectiva, contrariamente ao que acontece com a satisfação extrínseca. Por sua vez, Bouchard (1997) menciona que a satisfação intrínseca com o trabalho parece ser mais influenciada por factores genéticos do que a satisfação extrínseca (Hirschfeld, 2000).

No entanto, como refere Spector (1997), alguns autores questionam os conteúdos das subescalas (Cook, Hepworth, Wall \& Warr, 1981; Schriesheim, Powers, Scandura, Gardiner \& Landau, 1993), tendo sido encontradas fortes correlações entre as duas em vários estudos (Schmitt, Coyle, White \& Rauschenberger, 1978; Wexley, Alexander, Greenawalt \& Couch, 1980).

De igual modo, Hirschfeld (2000) refere que, apesar de existir distinção teórica entre satisfação intrínseca/extrínseca e evidência empírica que confirma a divisão do instrumento em duas subescalas (Arvey, Bouchard, Segal, \& Abraham, 1989; Arvey, McCall, Bouchard, Taubman, \& Cavanaugh, 1994; Day \& Bedeian, 1991) alguns investigadores (Arvey, Dewhirst \& Brown, 1978; Cook et al., 1981; Hepworth, Wall \& Warr, 1981; Schriesheim et al., 1993; Spector, 1997) sugerem que as subescalas como definidas pelos autores no manual do MSO- versão reduzida, revelam uma validade de constructo inferior ao que seria desejável.

Neste sentido, Schriesheim et al. (1993, cit in Hirschfeld, 2000) conduziram uma revisão das subescalas, verificando que o conteúdo das mesmas é questionável. 
Assim, dois itens considerados gerais pelos autores da versão original medem afinal a satisfação extrínseca; três itens incluídos na MSOE da versão original medem simultaneamente satisfação intrínseca e extrínseca; um dos itens da MSOI original inclui-se neste seu estudo na MSOEF; e outro item da MSOQ original mede satisfação intrínseca e extrínseca (Hirschfeld, 2000). Assim, sugerem que a MSOl deverá incluir os itens 1, 2, 3, 7, 9, 10, 11, 15,16 e 20 e a MSOEE, os itens 5, 6, 8, 12,17 e 18, passando a existir 4 itens gerais $(4,13,14$ e 19). Os itens incluídos nas duas versões podem ser visualizados no Quadro1.

Quadro 1. Itens do MSO - versão reduzida na sua forma original e revista

\begin{tabular}{|c|c|c|}
\hline Itens do MSO - versão reduzida & Original & Revista \\
\hline 1. Ser capaz de me manter ocupado(a) durante todo o tempo. & MSOQI & MSOQI \\
\hline $\begin{array}{l}\text { 2. Possibilidade de trabalhar de modo independente no meu } \\
\text { cargo. }\end{array}$ & MSOI & MSOQI \\
\hline 3. Oportunidade de fazer coisas diferentes de tempos a tempos. & MSOI & MSOQI \\
\hline 4. Oportunidade de "ser alguém na vida". & MSQI & Geral \\
\hline $\begin{array}{l}\text { 5. Modo como o meu superior lida com os seus } \\
\text { subordinados(as). }\end{array}$ & MSOE & MSQDE \\
\hline 6. Competência do meu supervisor na tomada de decisões. & MSQE & MSQE \\
\hline $\begin{array}{l}\text { 7. Possibilidade de fazer coisas que não vão contra a minha } \\
\text { consciência/valores. }\end{array}$ & MSOI & MSOLI \\
\hline 8. Segurança/estabilidade que o meu emprego me fornece. & MSOI & MSQE \\
\hline 9. Possibilidade de ajudar outras pessoas. & MSOI & MSOLI \\
\hline 10. Possibilidade de dizer às pessoas o que fazer. & MSOI & MSOQI \\
\hline $\begin{array}{l}\text { 11. Possibilidade de fazer algo em que faça uso das minhas } \\
\text { competências. }\end{array}$ & MSOI & MSOQI \\
\hline 12. Forma como as políticas da instituição são implementadas. & MSOE & MSQE \\
\hline 13. Meu salário e da quantidade de trabalho que realizo. & MSOE & Geral \\
\hline 14. Possibilidade de progressão profissional. & MSOE & Geral \\
\hline 15. Possibilidade de tomada de decisões por mim próprio(a). & MSOI & MSOLI \\
\hline $\begin{array}{l}\text { 16. Possibilidade de utilização dos meus próprios métodos para } \\
\text { a realização do meu trabalho. }\end{array}$ & MSODI & MSOQI \\
\hline 17. Condições de trabalho. & Geral & MSQE \\
\hline 18. Modo como os meus colegas se relacionam entre si. & Geral & MSQDE \\
\hline 19. Reconhecimento por fazer um bom trabalho. & MSOE & Geral \\
\hline 20. Sentimento de realização pessoal que obtenho no trabalho. & MSOI & MSOQI \\
\hline
\end{tabular}


Hirschfeld (2000) procurou esclarecer estas questões de validade, explorando se a revisão das subescalas (efectuada por Schriesheim et al., 1993) resulta em diferenças no estudo da satisfação com o trabalho.

Na sua investigação, efectuou algumas alterações à constituição das subescalas pois considerou que apesar de Schriesheim et al. (1993) incluírem (tal como os autores do instrumento) os itens 1, 2 e 10 na MSOI, estes podem ser problemáticos. Assim sendo, retirou-os da versão revista do MSOI. O autor fundamentou estas alterações na perspectiva de Cook et al. (1981), que salientam o facto de alguns itens não representarem aspectos universalmente valorizados no que concerne à satisfação com o trabalho. Para além disso, também comentaram a diferença substancial entre o número de itens na MSOI (12 itens), e na MSOQE (6 itens). Hirschfeld (2000), ao retirar estes três itens reduz a diferença entre o número de itens das duas subescalas. No seu estudo (constituído por duas amostras de participantes), o autor incluíu variáveis relacionadas com a satisfação laboral presentes em vários modelos teóricos, de forma a explorar as questões de validade.

No âmbito da análise da consistência interna das subescalas verificou que: para a amostra 1, o coeficiente alfa de Cronbach foi de .85 para a MSOI original, .83 para a MSOI revista (sem os três itens referidos anteriormente), .82 para a MSOE original e MSOE revista; para a amostra 2, a MSOI original revelou um coeficiente alfa de Cronbach de .84, a MSOI revista apresentou uma consistência interna de .82, e as MSOE original e revista obtiveram .88 de consistência interna (Hirschfeld, 2000).

Verificou, ainda, que a correlação entre a MSOI original e a versão revista foi de .96 (nas duas amostras), e que, entre a MSQE original e revista foi de .89 para a amostra 1, e de .92 para a amostra 2. Quanto à correlação entre MSOI e MSOE, na amostra 1 foi de .70 para a original, e de .73 para a revista. Na amostra 2, a correlação entre as subescalas foi de .56 , quer para a versão original, quer para a revista (Hirschfeld, 2000).

Hirschfeld (2000) constatou, também, que a satisfação intrínseca e extrínseca são componentes distintas (na versão original e na revista), e que as características psicométricas da versão original são equivalentes às da versão revista, tal como acontece com a validade de constructo. Para explicar estas semelhanças, sugeriu que os itens que se mantiveram nas duas versões constituem o núcleo central da satisfação intrínseca (os itens 3, 7, 9, 11, 15, 16 e 20, são os que apresentaram coeficientes mais elevados na análise factorial original e revista, com resultados de pelo menos .6o, e em média .69, enquanto que, para os restantes itens, a média foi de .48) e extrínseca (os itens 5, 6 e 12 apresentaram coeficientes na análise factorial da versão original e revista de .89). Assim, de acordo com o autor, o modelo de dois factores resulta de forma mais eficaz do que a possibilidade da escala incluir apenas um factor. No entanto, alerta que, quer um modelo, quer o outro, 
apresentam resultados abaixo do que seria aceitável, o que sugere a necessidade de mais estudos neste âmbito (Hirschfeld, 2000).

A análise destas características psicométricas da versão reduzida do MSO revela-se fundamental pelas vantagens indiscutiveis da sua utilização, ao constituir-se como um instrumento de fácil e rápida utilização, aplicável a qualquer organização permitindo, por um lado, aceder à satisfação dos trabalhadores, podendo ser, por outro, utilizado na exploração de necessidades vocacionais em estudos no âmbito do aconselhamento (Weiss, Dawis, England, \& Lofquist, 1967).

\section{Estudo empírico}

\subsection{Objectivos}

O objectivo principal do presente estudo centra-se na exploração das propriedades psicométricas do MSO - versão reduzida, aplicado em contexto português.

Para Saane et al. (2003), um instrumento com características psicométricas adequadas deve apresentar consistência interna e validade convergente elevadas. Neste sentido, procurou-se verificar a consistência interna da escala total e respectivas subescalas, bem como analisar a sua validade convergente com base nos resultados de outro instrumento de avaliação da satisfação com o trabalho, o Cuestionario de Satisfaccion S2O/23 (Meliá \& Peiró, 1989). Segundo Lloyd, Streiner e Shannon (1998), a validade convergente de um instrumento é o grau de semeIhança entre os resultados desse instrumento e os de outro que supostamente mede os mesmos constructos.

A par destas análises, pretende-se explorar a estrutura factorial do instrumento que, teoricamente, avalia duas dimensões (intrínseca e extrínseca) da satisfação com o trabalho.

\subsection{Método}

\subsubsection{Participantes}

A amostra é constituída por 136 participantes (93 do sexo feminino, correspondendo a $68.9 \%$ da amostra e 42 do sexo masculino, isto é, $31.1 \%$, sendo que um dos participantes não assinalou a sua resposta nesta questão de caracterização geral), provenientes de diferentes regiões do país.

A média de idades foi de 36.60 ( $D P=9.72$ ), variando entre 21 e 60 anos. Relativamente ao estado civil, constata-se que 62 são casados e 52 são solteiros, constituindo $83.8 \%$ da amostra. A média do número de filhos não chega a 1, variando entre o e 3 . 
Relativamente ao nivel educacional, apesar de se pretender uma amostra diversificada, verifica-se uma maior prevalência de participantes com formação de nível superior (94). Os restantes a presentavam habilitações ao nível do ensino secundário (37), e do nível do ensino básico (13). No que concerne à área de formação, a diversidade é maior: ciências sociais e humanas, educação/ensino, economia, ciências, engenharia/tecnologias, artes, comunicação, desporto, línguas, serviço militar, saúde, direito e turismo. Consequentemente, os grupos profissionais que participaram no estudo são também diversos, embora se destaque a adesão dos professores (de diferentes níveis de ensino) com 53 participantes, seguidos de profissionais da área da economia (economistas, empresários, contabilistas e administrativos) e das ciências sociais e humanas (psicólogos, sociólogos e educadores sociais).

O tempo médio de permanência no actual emprego é de 135.99 meses (cerca de 11 anos), variando entre 1 e 37 anos.

Constatou-se, também, que a distribuição ao nível da profissão dos respectivos cônjuges se assemelha à referida para os participantes, ou seja, a maioria são professores e profissionais da área da economia.

Para o estudo da estabilidade teste-reteste, foi seleccionada uma subamostra de 26 participantes.

\subsubsection{Instrumentos}

Foram utilizados três instrumentos de forma a obter os resultados necessários ao cumprimento dos objectivos referidos anteriormente.

\section{Questionário de Caracterização Geral}

Os participantes preencheram um breve questionário de caracterização sócio-demográfica constituído por duas partes: (1) caracterização geral (idade, sexo, localidade, estado civil, número de filhos, habilitações académicas, área de formação, profissão e ocupação do cônjuge); e (2) situação profissional actual (estabilidade - há quanto tempo desempenha actual profissão; satisfação actual com o trabalho numa escala de 4 pontos - muito insatisfeito, insatisfeito, satisfeito e muito satisfeito; e sucesso profissional actual também numa escala de 4 pontos - muito sucesso, algum sucesso, pouco sucesso, nenhum sucesso).

Quase todas as questões eram de resposta fechada. As de resposta aberta foram categorizadas (área de formação, profissão e ocupação do cônjuge) de forma a realizar as análises estatísticas necessárias. 


\section{Minnesota Satisfaction Questionnaire - Short Form}

Para avaliar a satisfação com o trabalho, na sua dimensão intrínseca e extrínseca, foi utilizado o Minnesota Satisfaction Questionnaire - Short Form (Weiss, Dawis, England, \& Lofquist, 1967), que inclui 20 itens retirados da versão longa do instrumento organizados em duas subescalas (cf. Quadro 1).

Cada item é respondido pelo trabalhador numa escala de 5 pontos: muito insatisfeito (cotação 1), insatisfeito (cotação 2), indeciso (cotação 3), satisfeito (cotação 4) e muito satisfeito (cotação 5). Assim, a pontuação total do instrumento pode variar entre 20 e 100 (entre 12 e 60 para a subescala de satisfação intrínseca e entre 6 e 30 para a subescala de satisfação extrínseca).

Relativamente às propriedades psicométricas, para a escala total, os autores reportaram um coeficiente geral de fidelidade de .87. Também existe alguma evidência empírica que suporta a existência de validade divergente para as duas componentes da satisfação com o trabalho nas suas relações com outras variáveis relevantes (estudos de Brown, 1996; Moorman, 1993; Bouchard, 1997).

\section{Cuestionario de Satisfaccion $520 / 23$}

Este instrumento foi concebido para avaliar a satisfação com o trabalho segundo um modelo teórico de cinco dimensões: (1) satisfação com supervisão; (2) satisfação com ambiente físico de trabalho; (3) satisfação com benefícios e políticas da organização; (4) satisfação intrínseca com o trabalho; e (5) satisfação com a participação (Carlotto \& Câmara, 2008). O S20/23 é o resultado da revisão do Cuestionario de Satisfacción $\mathrm{S}_{4} / 82$ mediante um processo de análise e selecção de 23 itens baseados em orientações teóricas e evidência empírica (Meliá, Pradilla, Martí, Sancerni, Oliver, \& Tomás, 1990, cit in Carlotto \& Câmara, 2008).

Os itens são cotados numa escala de 7 pontos: muito insatisfeito (cotação 1), bastante insatisfeito (cotação 2), algo insatisfeito (cotação 3), indiferente (cotação 4), algo satisfeito (cotação 5), bastante satisfeito (cotação 6) e muito satisfeito (cotação 7).

De acordo com os autores, apresenta um coeficiente alfa de Cronbach de .92, e há evidência empírica quanto à sua validade de constructo, demonstrada por exemplo, no estudo de Carlotto e Câmara (2008).

\subsubsection{Procedimento}

Os processos de tradução e retroversão necessários à aplicação do MSQ - versão reduzida e do $\mathrm{S}_{20} \mathrm{O} / 23$ foram essenciais para a sua utilização em contexto português, após ter sido pedida permissão (devidamente autorizada) à University of Minnesota - Vocational Psychology Research e a Meliá e Peiró, respectivamente. 
Os instrumentos foram aplicados a um pequeno grupo, que através da reflexão falada, detectou a necessidade de realizar alguns ajustes ao nível da linguagem, não se verificando, no entanto, problemas de compreensibilidade dos itens.

A selecção da amostra foi por conveniência, cumprindo, apenas, o critério do trabalhador exercer a sua função há pelo menos 1 ano. Procurou-se incluir uma diversidade de sectores laborais e regiões do país.

A recolha dos dados foi realizada no ano de 2009 , de duas formas distintas: contactos pessoais e via electrónica, procurando-se, para o efeito, que o número de participantes provenientes dos dois processos de recolha fosse semelhante, tal como sugere Pallant (2001).

No total foram contactados 136 trabalhadores, sendo que 60 participantes ( $44.1 \%$ da amostra) foram contactados pessoalmente (contactos pessoais), e os restantes 76 (55.9\% da amostra) foram contactados por e-mail (convidados a participar na recolha de dados preenchendo os instrumentos disponiveis online). Em ambas as situações, o objectivo do estudo foi esclarecido junto dos participantes, bem como garantida a confidencialidade e anonimato no tratamento dos dados.

Comparando as respostas dos questionários em papel e em formato electrónico verificou-se que não existem diferenças significativas quanto ao sexo dos participantes, estado civil, número de filhos, área de formação e ocupação do cônjuge. Resultados semelhantes foram encontrados no estudo de Field, Holley e Armenakis (1978) no âmbito da satisfação com o trabalho, não se verificando diferenças significativas entre os dois formatos, o que sugere que os inquéritos respondidos via internet podem ser usados sem afectar os resultados ou produzir enviesamentos nas respostas.

O tempo total necessário para o preenchimento dos instrumentos foi de aproximadamente 15 minutos.

No estudo de fidelidade com base no critério de estabilidade, uma sub-amostra de 26 participantes foi contactada num intervalo temporal de aproximadamente um mês depois da primeira aplicação dos instrumentos.

\subsection{Resultados}

A análise quantitativa dos dados foi realizada com o recurso ao Statistical Package for the Social Sciences - SPSS (versão 16.0) e envolveu duas etapas.

A primeira etapa centrou-se em análises mais gerais, de carácter descritivo, comparação entre grupos e relação entre variáveis. Efectuaram-se análises prévias 
de forma a determinar a normalidade da distribuição e verificar a existência de outliers susceptíveis de influenciar significativamente os resultados.

Numa segunda fase foram explorados os objectivos do presente estudo, centrados nas qualidades psicométricas do MSO - versão reduzida: (1) verificação da consistência interna da escala total e respectivas subescalas e dos respectivos coeficientes de estabilidade (intervalo de um mês); (2) análise da validade convergente com base na correlação dos resultados obtidos no MSO com os resultados do S20/23; e (3) exploração da estrutura factorial do instrumento através da realização de uma análise factorial exploratória.

A análise da distribuição através do teste de Kolmogorov-Smirnov revelou não estarem cumpridos os pressupostos da normalidade ( $p$.05) nos dados relativos às questões de avaliação da satisfação actual e sucesso actual incluídas no questionário de caracterização sócio-demográfica, bem como no resultado total do MSO - versão reduzida e do S20/23, o que de acordo com Pallant (2001) é bastante comum em grandes amostras.

Aliás, pela análise da assimetria e curtose destas variáveis foi possível constatar que estas não são iguais a zero. Contudo, Pallant (2001) relembra que esta ocorrência é comum em investigação na área das ciências sociais. O autor salienta, ainda, que é de esperar que em medidas de satisfação (por exemplo, satisfação com a vida) a assimetria seja negativa (como se verificou neste estudo) para reflectir o constructo subjacente (a maioria das pessoas encontra-se relativamente satisfeita). Verificaram-se também resultados positivos para a curtose o que indica que não há valores extremos nas respostas dos participantes (como foi confirmado pela inexistência de outliers).

\section{Resultados de carácter descritivo}

No âmbito da caracterização sócio-demográfica os participantes foram questionados sobre a sua satisfação geral com o trabalho e sucesso actual ao nivel profissional (ambos cotados numa escala de quatro pontos). Em média, os participantes revelam-se relativamente satisfeitos com a sua situação laboral ( $M=$ 2.90, $\mathrm{DP}=.82$ ), e consideram que têm algum sucesso profissional no presente $(M=3.13, D P=.54)$.

São apresentados no Quadro 2, médias, desvios-padrão, mínimos e máximos obtidos no MSO - versão reduzida e respectivas subescalas, da versão original, da versão revista, e das alterações efectuadas por Hischfeld no seu estudo realizado em 2000. 
Quadro 2. Médias, desvios-padrão, mínimos e máximos no MSQ-versão reduzida e subescalas

\begin{tabular}{lccccc}
\hline & N & $M$ & DP & Min & Max \\
\hline MSOI original & 130 & 47.61 & 7.62 & 26 & 60 \\
\hline MSOE original & 132 & 19.36 & 5.62 & 6 & 30 \\
\hline MSOI revista & 130 & 40.11 & 6.47 & 19 & 50 \\
\hline MSOQE revista & 131 & 20.84 & 4.96 & 9 & 30 \\
\hline MSOI (Hirschfeld, 2000) & 131 & 28.03 & 4.99 & 11 & 35 \\
\hline MSO Total & 126 & 74.31 & 13.78 & 39 & 100 \\
\hline
\end{tabular}

A média no MSQ - versão reduzida foi de 74.31 (DP = 13.78) o que revela uma satisfação moderada com o trabalho. Os participantes revelam-se mais satisfeitos com os aspectos da dimensão intrínseca (quer na versão original quer na revista), em comparação com os factores extrínsecos associados à satisfação com o trabalho.

Ao nivel dos itens, apenas dois não tiveram respostas de cotação 1 (muito insatisfeito): item 1 (capaz de se manter ocupado) e item 10 (possibilidade de dizer às pessoas o que fazer). A média mais alta $(M=4.20, D P=.88)$ verificou-se no item 9 (possibilidade de ajudar outras pessoas), enquanto que a mais baixa ( $M=3.01$, $\mathrm{DP}=1.24)$ foi visível no item 13 (salário e quantidade de trabalho).

No S 20/23 a média encontrada foi de 110.07 ( $D P=26.16$ ), num total possivel de 161, o que revela também uma satisfação moderada dos participantes.

\section{Comparação entre grupos}

Nas análises comparativas entre grupos, com base na faixa etária, verificou-se que os participantes com mais de 50 anos apresentaram resultados mais elevados de satisfação no item 8 (segurança e estabilidade) do MSO - versão reduzida ( $M$ $=4.10, S D=.85)$, seguidos dos participantes com idades compreendidas entre 31 e 49 anos $(M=3.79, D P=1.05)$ e, por fim, pelos participantes mais novos $(M=$ 3.43, $\mathrm{DP}=1.09)$.

Ao tentar perceber se estas diferenças eram significativas (utilizado o procedimento One-Way ANOVA, depois de verificado que não era violado o pressuposto de homogeneidade das variâncias), constatou-se que as diferenças encontradas eram significativas $[F(2,133)=3.46, p=.04]$. Depois de calculado o tamanho do efeito para a população ( $d$ de Cohen), concluiu-se que este era baixo (eta ${ }^{2}=.05$ ). O recurso ao teste de Turkey demonstrou diferenças significativas apenas entre os participantes com mais de 50 anos e os com menos de 30 anos ( $p<.05$ ). 


\section{Relação entre variáveis}

$\mathrm{Na}$ análise das relações entre variáveis verificaram-se algumas associações entre os resultados do MSO - versão reduzida e (1) as habilitações académicas dos participantes, (2) a satisfação actual e (3) o sucesso actual (itens avaliados no questionário de caracterização sócio-demográfica).

Constatou-se uma correlação positiva, embora fraca $(r=.28, p=.001)$, entre a satisfação total com o trabalho medida pelo MSO - versão reduzida e as habilitações académicas dos participantes. Esta variável relacionou-se, ainda, de forma positiva e fraca, com os resultados da MSOI original ( $r=.28, p=.002)$ e MSQE original $(r=.19, p<.05)$. Por sua vez, correlacionou-se positiva e moderadamente com a MSOI revista $(r=.32, p<.001)$ e com a MSOI revista, utilizada no estudo realizado em 2000 por Hirschfeld $(r=.34, p<.001)$.

Verificaram-se, também, associações moderadas e positivas entre os resultados totais no MSO - versão reduzida e as respostas às questões do questionário de caracterização sócio-demográfica relacionadas com o sucesso actual $(r=.44, p<$ .001) e a satisfação actual ( $r=.42, p<.001)$.

A satisfação actual e o sucesso actual revelaram-se positiva e moderadamente correlacionados com os resultados da MSOI original $(r=.40, p<.001$ e $r=.48$, $p<.001$ respectivamente) e da MSOEE original $(r=.37, p<.001$ e $r=.36, p<.001$ respectivamente).

Resultados semelhantes foram encontrados para a versão revista do instrumento. Assim, a satisfação actual e o sucesso actual apresentaram correlações positivas e moderadas com a MSOI revista $(r=.39, p<.001$ e $r=.47, p<.001$ respectivamente) e a MSOE revista ( $r=.32, p<.001$ e $r=.34$, $p<.001$, respectivamente). Relativamente à sua relação com a MSOI utilizada no estudo de Hirschfeld (2000), uma vez mais surgiram correlações positivas e moderadas $(r=.37, p<.001$ ao nível da satisfação e $r=.44, p<.001$ no que concerne ao sucesso).

Salienta-se, também, a associação positiva e moderada entre estas duas questões, satisfação actual e sucesso actual $(r=.30, p<.001)$.

\section{Propriedades psicométricas do MSQ - versão reduzida}

Para o efeito, foram analisados dois indicadores psicométricos, nomeadamente a fidelidade (consistência interna e estabilidade) e validade (convergente), no sentido de verificar se o MSO - versão reduzida é um instrumento adequado na avaliação da satisfação com o trabalho.

Procedeu-se, também, à análise factorial do instrumento, a fim de verificar a sua estrutura subjacente. 


\section{Análise da consistência interna e da estabilidade (teste-reteste)}

O Quadro 3 apresenta os valores do coeficiente alfa de Cronbach para o instrumento total e por subescala (na sua versão original, revista e como foi utilizada no estudo de Hirschfeld, 2000).

O cálculo do coeficiente alfa de Cronbach para a escala total revelou um valor de fidelidade elevado (.93), apontando para uma adequada consistência interna do instrumento. Relativamente às subescalas, o valor mais baixo (.82) corresponde à subescala de satisfação extrínseca da versão revista. Aliás, as duas subescalas da versão original apresentam os valores mais elevados de consistência interna.

Quadro 3. Valores do coeficiente alfa de Cronbach para o MSO - versão reduzida e respectivas subescalas.

\begin{tabular}{lcc}
\hline & Alfa de Cronbach & Número de Itens \\
\hline MSO Total & .93 & 20 \\
\hline MSOI original & .89 & 12 \\
\hline MSOE original & .87 & 6 \\
\hline MSOI revista & .88 & 10 \\
\hline MSOE revista & .82 & 6 \\
\hline MSOI revista (Hirschfeld, 2000) & .85 & 7 \\
\hline
\end{tabular}

Apesar de algumas subescalas incluírem um reduzido número de itens (menor que 10), nenhuma apresentou resultados abaixo do que é desejável (.70), como recomendado por Nunnally (1978, cit in Pallant, 2001).

Nenhum dos itens das subescalas MSOI original, MSOE original, MSOI revista e MSOI revista (Hirschfeld, 2000) aumenta o valor de alfa da respectiva subescala, se retirado. No entanto, se excluirmos o item 8 (segurança e estabilidade) da MSOE revista, verifica-se uma ligeira subida do valor de alfa da subescala quando retirado.

Apresenta-se, no Quadro 4, os resultados do coeficiente de correlação de Pearson entre as subescalas e entre estas e a nota global.

Quadro 4. Intercorrelações entre subescalas e nota global no MSO - versão reduzida

\begin{tabular}{|c|c|c|c|c|c|c|}
\hline & $\begin{array}{l}\text { MSO } \\
\text { Total }\end{array}$ & 1 & 2 & 3 & 4 & 5 \\
\hline 1. MSOI original & $.96^{\prime \prime}$ & & & & & \\
\hline 2. MSOE original & $.93^{\prime \prime}$ & $.79^{* *}$ & & & & \\
\hline 3. MSOI revista & $.93^{* *}$ & $.98^{* *}$ & $.75^{* *}$ & & & \\
\hline 4. MSOE revista & $.91^{*}$ & $.79^{\prime \prime}$ & $.91^{* \prime}$ & $.74^{\prime \prime}$ & & \\
\hline 5. MSOI revista (Hirschfeld, 2000) & $.91^{*}$ & $.96^{* *}$ & $.73^{* *}$ & $.98^{* *}$ & $.72^{* *}$ & \\
\hline
\end{tabular}


Existem correlações fortes entre todas as subescalas e a nota global, bem como entre as diferentes subescalas. As correlações mais elevadas, com o resultado total, surgem em relação às subescalas da versão original.

Ao nível dos itens, foi possível constatar que, na sua totalidade, estes apresentam correlações moderadas e fortes, com a nota total. O item 17 (condições de trabalho) apresenta-se com a correlação mais elevada $(r=.78)$. O valor de correlação mais baixo, mas ainda assim moderado $(r=.45$ ), foi o encontrado no item 8 (segurança e estabilidade).

Quanto aos coeficientes de estabilidade obtidos, estes são também bastante adequados, mesmo atendendo ao tamanho reduzido da amostra (26 participantes). A análise das correlações teste-reteste mostra que a maioria dos coeficientes se situam acima de .80 , revelando uma adequada estabilidade temporal do instrumento (entre a aplicação no primeiro momento - $\mathrm{T}_{1}$ - e no segundo momento temporal - T2), como se pode verificar no Quadro 5 .

Quadro 5. Coeficientes de estabilidade para o MSQ - versão reduzida

\begin{tabular}{|c|c|c|c|c|c|c|}
\hline & $1\left(\mathrm{~T}_{1}\right)$ & $2\left(\mathrm{~T}_{1}\right)$ & $3\left(\mathrm{~T}_{1}\right)$ & $4\left(T_{1}\right)$ & $5\left(\mathrm{~T}_{1}\right)$ & $6(\mathrm{~T} 1)$ \\
\hline 1. MSO Total ( $\left.\mathrm{T}_{2}\right)$ & $.86^{\prime \prime}$ & $.83^{* *}$ & $.78^{* *}$ & $.76^{\prime \prime}$ & $.77^{* *}$ & $.77^{* *}$ \\
\hline 2. MSOI original (T2) & $.78^{\prime \prime}$ & $.83^{* *}$ & $.63^{* *}$ & $.79^{\prime \prime}$ & $.62^{* \prime}$ & $.82^{* *}$ \\
\hline 3. MSOE original (T2) & $.82^{\prime \prime}$ & $.69^{\prime \prime}$ & $.85^{* *}$ & $.59^{\prime \prime}$ & $.83^{\prime \prime}$ & $.60^{* \prime}$ \\
\hline 4. MSOI revista $\left(\mathrm{T}_{2}\right)$ & $.80^{\prime \prime}$ & $.85^{\prime \prime}$ & $.62^{* *}$ & $.85^{*}$ & $.61^{*}$ & $.88^{*}$ \\
\hline 5. MSOE revista $\left(\mathrm{T}_{2}\right)$ & $.82^{\prime \prime}$ & $.73^{*}$ & $.80^{\prime \prime}$ & $.59^{* \prime}$ & $.89^{\prime \prime}$ & $.58^{* *}$ \\
\hline $\begin{array}{l}\text { 6. MSOI revista } \\
\text { (Hirschfeld, 2000) (T2) }\end{array}$ & $.80^{* \prime}$ & $.84^{\prime \prime}$ & $.64^{* *}$ & $.83^{\prime \prime}$ & $.63^{*}$ & $.88^{* *}$ \\
\hline
\end{tabular}

\section{Exploração da validade convergente do MSQ - versão reduzida}

A validade convergente neste estudo foi explorada através da correlação entre os resultados do MSO - versão reduzida e os resultados de outro instrumento que, supostamente, mede o mesmo constructo (como sugerem Lloyd, Streiner, \& Shannon,1998), o $S$ 20/23.

Tal como esperado, para verificar a validade convergente do MSO - versão reduzida, todas as correlações entre os resultados dos dois instrumentos foram fortes. Salienta-se a correlação de .84 entre os resultados totais do MSQ - versão reduzida e o $520 / 23$.

No Quadro 6, podem ser consultadas as correlações entre o MSQ - versão reduzida (e respectivas subescalas) e o $520 / 23$. 
Quadro 6. Correlações entre o MSQ - versão reduzida e o S 20/23

272

\begin{tabular}{lc}
\hline & S 20/23 Total \\
\hline MSOI original & $.76^{* \prime}$ \\
\hline MSOQE original & $.81^{* \prime}$ \\
\hline MSOI revista & $.73^{* \prime}$ \\
\hline MSOE revista & $.84^{* \prime}$ \\
\hline MSOI revista (Hirschfeld, 2000) & $.72^{* \prime}$ \\
\hline MSO Total & $.84^{* \prime}$ \\
\hline
\end{tabular}

A correlação mais baixa (.72) assinala-se entre a MSOI revista, utilizada no estudo de Hirschfeld (2000), e o S 20/23 total. Relativamente às subescalas, a MSOI original correlaciona-se mais fortemente com o S 20/23, do que com a sua versão revista. Contudo, no que concerne à MSOE, a versão revista apresenta um resultado de correlação superior com o S 20/23.

\section{Análise factorial exploratória}

A análise dos pressupostos essenciais para a realização da análise factorial permitiu concluir que o número de participantes se revela suficiente (cinco participantes por item), tendo em conta as recomendações de Pallant (2001). Também a exploração da matriz de correlação revela resultados acima de .30 para quase todos os itens. Salienta-se, contudo, a existência de dois itens mais problemáticos a este nivel: item 18 (modo como os colegas se relacionam) e, em seguida, o item 9 (possibilidade de ajudar outras pessoas). Verificou-se, ainda, que o valor de Kaiser-Meyer-Olkin Measure of Sampling Adequacy (.89) é superior a .6, e que o valor de significância de Bartlett's Test of Sphericity é inferior a .05 ( $p=.000)$.

A extracção de factores com base no critério de Kaiser (eigenvalue superior a 1) apontou para a existência de 4 componentes $(8.839,1.496,1.190$ e 1.013) que explicam no total $62.69 \%$ da variância. A visualização do screeplot, permite-nos constatar que a percentagem de variância explicada é maior pela primeira componente do que pelas seguintes. No entanto, também a segunda componente revela uma ligeira mudança na forma do plot. Na análise da matriz de componente, verifica-se que a maioria dos itens apresenta saturações superiores a .4 na primeira e na segunda componente, excepto na terceira e a quarta. Deste modo, a estrutura que parece ser mais interpretável, é aquela que se organiza em 2 factores.

Assim, depois de realizada a rotação dos factores (varimax), retendo apenas duas componentes, verifica-se que a primeira componente explica $26.83 \%$ da variância e a segunda $24.96 \%$ (cf. Quadro 7). 
Quadro 7. Estrutura factorial do MSQ - versão reduzida

\begin{tabular}{|c|c|c|}
\hline Item & Factor 1 & Factor 2 \\
\hline 14. Possibilidade de progressão profissional. & .76 & \\
\hline 4. Oportunidade de "ser alguém na vida". & .70 & \\
\hline 12. Forma como as políticas da instituição são implementadas. & 69 & \\
\hline 13. Meu salário e da quantidade de trabalho que realizo. & .68 & \\
\hline 8. Segurança/estabilidade que o meu emprego me fornece. & .65 & \\
\hline $\begin{array}{l}\text { 5. Modo como o meu superior lida com os seus } \\
\text { subordinados(as). }\end{array}$ & .65 & \\
\hline 6. Competência do meu supervisor na tomada de decisões. & .63 & \\
\hline 17. Condições de trabalho. & .59 & \\
\hline 1. Ser capaz de me manter ocupado(a) durante todo o tempo. & .55 & \\
\hline $\begin{array}{l}\text { 7. Possibilidade de fazer coisas que não vão contra a minha } \\
\text { consciência/valores. }\end{array}$ & .52 & \\
\hline 16. Possibilidade de utilização dos meus próprios métodos. & & .76 \\
\hline 15. Possibilidade de tomada de decisões por mim próprio(a). & & .72 \\
\hline $\begin{array}{l}\text { 11. Possibilidade de fazer algo em que faça uso das minhas } \\
\text { competências. }\end{array}$ & & .72 \\
\hline 9. Possibilidade de ajudar outras pessoas. & & .72 \\
\hline $\begin{array}{l}\text { 2. Possibilidade de trabalhar de modo independente no meu } \\
\text { cargo. }\end{array}$ & & .64 \\
\hline 3. Oportunidade de fazer coisas diferentes de tempos a tempos. & & .58 \\
\hline 10. Possibilidade de dizer às pessoas o que fazer. & & .56 \\
\hline 20. Sentimento de realização pessoal que obtenho no trabalho. & & .56 \\
\hline 19. Reconhecimento por fazer um bom trabalho. & & .54 \\
\hline 18. Modo como os meus colegas se relacionam entre si. & & .39 \\
\hline Eigenvalue & $5 \cdot 366$ & 4.996 \\
\hline \% de variância explicada & $26.83 \%$ & $24.96 \%$ \\
\hline
\end{tabular}

Apesar da estrutura encontrada não ser simples, devido à associação de alguns itens às duas componentes, foi possível organizá-los de acordo com a sua saturação mais forte com um dos factores.

Observando o Quadro 7, verifica-se que os itens 2, 3, 9, 10, 11, 15, 16 e 20 saturam no factor 2, o que parece corresponder à satisfação intrínseca com o trabalho, tal como verificado na versão original e revista. A exclusão dos itens 2 e 10 da dimensão intrínseca, realizada por Hirschfeld (2000), parece não se adequar neste estudo.

Os itens com menor saturação no factor 2 são aqueles que, quer na versão original, quer na revista, não se associam à satisfação intrínseca. O item 19 na versão original surge na MSOE e na revista é considerado um item geral. O item 18, que já se tinha revelado problemático na matriz de correlação, foi considerado pelos autores como geral e como MSQE na revisão da escala. 
No factor 1, que por sua vez parece referir-se a aspectos de satisfação extrínseca, surgem os itens 5, 6 e 12 (tal como na versão original e revista). Os itens 4 (MSOL original), 13 (MSOE original) e 14 (MSQE original), considerados gerais na versão revista, emergem, aqui, na componente extrínseca. Por sua vez, o item 8 (MSOI original) e o item 17 (geral na versão original), tal como na versão revista, surgem associados à satisfação extrínseca. Tal como no estudo de Hirschfeld (2000), o item 1 (MSOI) parece problemático, pois enquadra-se na satisfação extrínseca. Finalmente, o item 7 surge na satisfação extrínseca, apesar de na versão original, revista e estudo de Hirschfeld (2000), estar associado à satisfação intrínseca.

\section{Discussão e conclusão}

Tendo em conta que a satisfação com o trabalho se repercute directamente no trabalhador e no funcionamento das organizações (Saane et al., 2003), os resultados obtidos neste estudo apontam para uma relativa satisfação com o trabalho nos 136 participantes, quer pela análise das respostas à questão de satisfação actual incluída no questionário de caracterização sócio-demográfica, quer pelos resultados obtidos no MSO - versão reduzida.

Aliás, a questão relativa à satisfação actual com o trabalho, incluída no questionário de caracterização sócio-demográfica, correlaciona-se de forma positiva e moderada com os resultados totais no MSQ - versão reduzida. Este facto parece sugerir que, nesta amostra, a avaliação da satisfação com o trabalho através de uma questão geral seria viável, reduzindo os custos inerentes à aplicação de um instrumento multidimensional que requer, necessariamente, mais tempo para o seu preenchimento. Apesar de Scarpello e Campbell (1983, cit in Wanous, Reichers, \& Hudy, 1997) defenderem a utilização de uma única questão de avaliação geral da satisfação com o trabalho, estes resultados merecem suporte empírico mais sustentado, como salientam Wanous, Reichers e Hudy (1997) no seu estudo, o qual obteve resultados muito superiores para a avaliação da satisfação com o trabalho através de um único item.

Não obstante, é indiscutivel a riqueza da informação relativa a aspectos especíicos da satisfação com o trabalho obtida com instrumentos multidimensionais. Por exemplo, neste estudo, a comparação entre grupos revelou diferenças em relação a aspectos específicos da satisfação com o trabalho, nomeadamente quanto à segurança e estabilidade.

Relembra-se que os participantes mais velhos parecem mais satisfeitos quanto a este aspecto. De acordo com Araújo (2009), na actualidade, as organizações públicas e privadas mantêm os seus colaboradores em situações laborais precárias e indese- 
jáveis (mais rentáveis para a organização que evita encargos fiscais), seja através do trabalho independente (Kovács, 2004), do subemprego (Marques, 2004), do trabalho temporário, entre outras. Saliente-se que, mesmo nas situações em que há contratação, esta é precária. As organizações mantêm os trabalhadores renovando continuamente os contratos a prazo, mas não passando a contratos sem termo (Araújo, 2009). Assim, é provável que os participantes mais velhos sejam colaboradores efectivos nas suas organizações, e por isso, sintam maior segurança e estabilidade laboral, comparativamente com os mais jovens. Neste sentido, seria interessante, em investigações futuras, explorar o tipo de vínculo laboral no trabalho, de forma a compreender se existem diferenças nas faixas etárias, assim como estudar outros indicadores que poderão estar associados às diferenças de satisfação no trabalho, como por exemplo, o salário e o tempo de permanência na organização actual.

Outro aspecto a investigar, nos próximos trabalhos, refere-se aos resultados superiores de satisfação encontrados nas dimensões mais intrínsecas relacionadas com a natureza do trabalho. Aliás, o item 9 do MSO - versão reduzida (possibilidade de ajudar outras pessoas), foi o que apresentou média mais elevada. De facto, "o nosso trabalho estrutura por inteiro a nossa relação com o mundo e as nossas relações sociais" (Araújo, 2009, 15), desempenhando um papel de reforço nas sociedades colectivas ao permitir que os indivíduos sejam parte activa de uma relação social e se integrem na comunidade (Araújo, 2009).

Por outro lado, no presente estudo, um dos aspectos extrínsecos que revelou resultados mais baixos de satisfação, foi o salário e a quantidade de trabalho realizada. Tendo em conta a conjuntura económica actual, este resultado pode ser compreendido na medida em que Portugal "tem hoje uma economia mais débil, com mais desemprego, mais desigualdades, mais precariedade laboral, menores salários" (Carvalho, 2006, 1).

Este cenário tem afectado, sobretudo, os trabalhadores com formação superior. "Sempre foi expectado que quem estudasse mais, teria maior probabilidade de emprego, o que hoje não é linear" no nosso país (Araújo, 2009, 14). A dificuldade dos licenciados em conseguir um emprego contraria essas expectativas. Deste modo, é provável que os participantes com habilitações académicas mais elevadas, pelo facto de conseguirem estar a trabalhar (há pelo menos um ano), apresentem resultados de satisfação em geral com o trabalho superiores aos participantes com habilitações académicas inferiores.

Nesta amostra, as questões da satisfação com o trabalho parecem associadas ao sucesso profissional. Na perspectiva de Pryor (1981), o sucesso profissional definese em função dos valores associados ao trabalho ou dos aspectos preferenciais do trabalho, por parte do trabalhador. Assim, os valores ou interesses associados ao trabalho, subjacentes à relação entre satisfação e sucesso profissional, apesar 
de não explorados neste trabalho, levantam pistas para investigações futuras em contexto nacional.

Após uma breve incursão pelos resultados mais descritivos, a discussão centrar-se-á nos objectivos deste trabalho, nomeadamente a análise das características psicométricas do MSO - versão reduzida, a plicado em Portugal.

O instrumento revelou propriedades psicométricas adequadas no que concerne à sua consistência interna (.93). Este valor é mais elevado que o encontrado pelos autores do instrumento (.87) e por Robert, Young e Kelly (2006) no seu estudo (.82).

Relativamente às subescalas, os resultados ao nível do coeficiente alfa de Cronbach também foram elevados, principalmente para as subescalas da versão original. Apesar das subescalas da versão revista por Schriesheim et al. (1993) também apresentarem resultados de consistência interna elevados, com base nesta amostra, parece-nos aconselhável o uso em contexto português da versão original do instrumento. Estes dados são confirmados pela análise das intercorrelações entre subescalas, e, entre estas e os resultados totais no MSO - versão reduzida.

O instrumento revela, assim, uma adequada fidelidade no que concerne à sua consistência interna, com resultados semelhantes (e por vezes superiores) aos encontrados na literatura.

Também ao nível dos coeficientes de estabilidade, os resultados obtidos revelam fortes correlações teste-reteste (acima de .80) para o intervalo temporal de aproximadamente um mês. Estes resultados corroboram a elevada fidelidade da escala no que concerne à estabilidade temporal, confirmada pelos autores (para a escala total, um coeficiente de .89 no período de uma semana e .70 no intervalo de um ano, Weiss et al., 1967) e noutros estudos (eg., Levinson, 1998) uma correlação teste-reteste para o resultado total de .89 , com um intervalo de uma semana, e de .70 com um intervalo de um ano.

De igual modo, ao nível da validade convergente os dados são bastante positivos, com base na comparação entre os resultados totais do MSO - versão reduzida e os do $\mathrm{S} 20 / 23$ (.84), verificando-se, o mesmo, ao nível das subescalas, o que sugere uma validade convergente adequada.

Assim sendo, conclui-se que o instrumento apresenta características psicométricas que justificam a sua ampla utilização no âmbito da avaliação da satisfação com o trabalho, também na população portuguesa.

A análise factorial exploratória permitiu constatar que o instrumento parece medir duas dimensões da satisfação com o trabalho, pela emergência de dois factores que explicam uma percentagem considerável da variância. Esta estrutura é con- 
sistente com a conceptualização teórica subjacente à construção do instrumento, que aponta para a medição da satisfação intrínseca e extrínseca com o trabalho.

Neste estudo, no que concerne à MSOLI, incluem-se os itens 2, 3, 9, 10, 11, 15, 16 e 20 tal como na versão original e revista. A exclusão dos itens 2 e 10 da MSOI realizada por Hirschfeld (2000) não parece adequar-se aos resultados obtidos com a presente amostra.

Apenas dois itens (os que apresentam valores mais baixos nesta análise das componentes) que surgiram na dimensão intrínseca não se adequam à MSOQI da versão original e revista, podendo, este facto, estar relacionado com uma especificidade cultural, que deve ser explorada no futuro.

$\mathrm{Na}$ versão original, o item 19 (reconhecimento pelo trabalho realizado) surge na MSOE, apontando para o reconhecimento externo pela realização de um bom trabalho. Na versão revista, é considerado um item geral (nem intrínseco, nem extrínseco). Na presente análise, é possível que a tradução do item tenha sugerido aos participantes a ideia dos mesmos reconhecerem que fazem um bom trabalho, embora no processo de tradução e retroversão não tenham sido criados problemas de compreensibilidade.

No mesmo sentido, o item 18 (relação entre colegas) surge, aqui, (embora em última posição de saturação) na MSOLI. Os autores consideram-no um item geral, enquanto que na versão revista, surge na MSOEE. Uma possivel explicação para este aspecto assenta na ideia de que, no contexto português, o participante, na avaliação da sua satisfação em relação ao clima relacional entre trabalhadores na organização, se tenha incluído nessas relações, valorizando a importância do trabalho em equipa no desempenho das suas tarefas.

No segundo factor (satisfação extrínseca) surgem os itens 5, 6 e 12 (em concordância com a versão original e revista). Do mesmo modo que na MSOQE original, também neste estudo os itens 13 e 14 surgem associados a esta dimensão (embora na versão revista fossem considerados gerais). Por sua vez, o item 8 (MSOl original), e o item 17 (geral na versão original), surgem associados à satisfação extrínseca, tal como na versão revista.

De salientar, que alguns itens que surgiram nesta componente extrínseca, não se incluem na respectiva subescala, quer na versão original, quer na revista.

O item 7 (consciência e valores) surge, neste estudo, na satisfação extrínseca, apesar de na versão original, revista e estudo de Hirschfeld (2000) estar associado à satisfação intrínseca. Os trabalhadores parecem considerar que a realização de acções que vai contra a sua consciência/valores não está associada ao trabalho em si, mas a factores sobre os quais não têm controlo. Poder-se-ia especular sobre a 
necessidade de cumprir ordens dos supervisores (independentemente dos valores morais pessoais) na realização das tarefas, tendo em conta o cenário económico descrito anteriormente, caracterizado pela elevada taxa de desemprego, e consequente necessidade do trabalhador manter o seu emprego. Estas especulações, mais uma vez, salientam a necessidade de suporte empírico em próximos estudos realizados em contexto nacional.

Também o item 4 ("ser alguém na vida"), foi entendido pelos participantes como algo externo, não relacionado com as tarefas do trabalho, embora na versão original tenha surgido na MSOI. Este resultado pode ser interpretado à luz das referências culturais do nosso país, que valoriza o estatuto social do indivíduo com base em critérios que vão para além da natureza do trabalho em si. Por outras palavras, há profissões que são mais valorizadas pela sociedade, independentemente das tarefas realizadas pelo trabalhador. Salienta-se, ainda, que a tradução deste item levantou algumas questões já que a expressão utilizada na versão original não tem tradução directa adequada em contexto português ("be somebody in the community"). No entanto, já no estudo de revisão este item levantou problemas passando a ser considerado geral.

Como sugere Hirschfeld (2000), também o item 1 (manter-se ocupado), incluido na MSOI (original e na revista) parece problemático pois enquadra-se na satisfação extrínseca. De facto, a valorização universal de alguns aspectos do trabalho deve ser alvo de mais investigação.

Em sintese, os itens que se mantiveram nas duas versões da MSOLI e MSOEE surgem, neste estudo, adequadamente associados às respectivas dimensões (com excepção do item 7, que se encontra associado à satisfação extrínseca).

Embora o modelo de dois factores tenha sido confirmado em vários estudos, Hirschfeld (2000) alerta para a necessidade de mais estudos neste âmbito. Em contexto nacional, a realização de uma análise factorial confirmatória parece-nos essencial. Independentemente da relevância dos resultados obtidos neste estudo, salienta-se a existência de algumas limitações que poderão constituir-se como uma base para investigações futuras. A possibilidade inovadora de utilizar o MSO- versão reduzida (e o S 20/23) em contexto português, permitiu encontrar algumas especificidades culturais que no futuro devem ser confirmadas. A título de exemplo, as limitações metodológicas associadas ao tamanho da amostra e à tradução do instrumento.

Em suma, este trabalho constitui-se como um contributo para o estudo da satisfação com o trabalho no que diz respeito à utilização do MSO - versão reduzida, ao providenciar uma adequada abordagem à medição deste constructo em Portugal e, simultaneamente, um incentivo à discussão teórica sobre o mesmo, ao demonstrar implicações para as práticas organizacionais. 


\section{Referências bibliográficas}

Araújo, P. (2009). "Os inimpregáveis": estudos de caso sobre os impactos psicossociais do não-emprego em licenciados portugueses. Dissertação de mestrado não publicada. Faculdade de Psicologia e de Ciências da Educação da Universidade do Porto.

Ahmadi, K., \& Alireza, K. (2007). Stress and Job Satisfaction among Air Force Military Pilots. Journal of Social Sciences, 3(3), 159-163.

Carlotto, M., \& Câmara, S. (2008). Propriedades psicométricas do Questionário de Satisfação no Trabalho (S2O/23). Psico-USF, 13(2), 203-210.

Carvalho, P. (2006). Reflexões sobre o Euro e seu impacto em Portugal. Revista electrónica $O$ Diário.info.23 Novembro: Consultado em Janeiro 2010, http://odiario.info/articulo. php? $=102 \&$ more $=1 \& c=1$.

Field, H., Holley, W., \& Armenakis, A. (1978). Computerized answer sheets: What effects on response to a mail survey? Educational and Psychological Measurement, 38(3), 755-759.

Hackman, J., \& Oldham G. (1976). Motivation through the design of work: test of a theory. Organizational Behaviour Human Performance, 16, 250-279.

Herzberg, F., Mausner, B., \& Snyderman, B. (1959). The Motivation to Work. New York: John Wiley. Hirschfeld, R. (2000). Does revising the intrinsic and extrinsic subscales of the Minnesota Satisfaction Questionnaire short form make a difference. Educational Psychology Measure, 60, 255-270.

Kovács, I. (2004). Emprego flexível em Portugal. Sociologias, 12, 32-67. Consultado em Janeiro 2010, http://www.scielo.br/pdf/soc/n12/22256.pdf.

Jewell, L., Beavers, K., Kirby, B. M., \& Flowers, J. (2001). Relationships between levels of job satisfaction expressed by North Carolina vocational agriculture teachers and their perceptions toward the agricultural education teaching profession. Journal of Agricultural Education, 31(1), 52-57.

Lawler, E. \& Hall, D. (1970). Relationship of job characteristics to job involvement, satisfaction and intrinsic motivation. Journal of Applied Psychology, 54, 305-312.

Lester, P. E. (1982). Teacher Job Satisfaction Questionnaire (TJSQ). Manuscrito não publicado. Long Island University.

Levinson (1998). Stress, Burnout and Dissatisfaction in School Psychology. Consultado em Janeiro 2010, http://www.coe.iup.edu/emlevins/aspp2/index.htm.

Lloyd, S., Streiner, D., \& Shannon, S. (1998). Predictive validity of the emergency physician and global job satisfaction instruments. Academic Emergency Medicine, 5, 234-241.

Locke, E. (1976). The nature and causes of job satisfaction, in M. Dunnette (Ed.) Handbook of Industrial and Organizational Psychology. Chicago: Rand McNally.

Marques, A. (2004). Mercados profissionais e (di)visões identitárias de jovens engenheiros. Consultado em Janeiro 2010, http://ler.letras.up.pt/uploads/ficheiros/271.pdf.

Meliá, J., \& Peiró, J. (1989). La medida de satisfacción laboral en contextos organizacionales: El Cuestionario de satisfacción S2O/23. Psicothema, 5, 59-74.

Ngo, D. (2009). Minnesota Satisfaction Questionnaire. Consultado em Outubro 2009, http:// www.humanresources.hrvinet.com/minnesota-satisfaction-questionnaire-msq/

Pallant, J. (2001). SPSS Survival Manual. Buckingham: Open University Press.

Pryor, R. (1981). Interests and values as preferences: a validation of the Work Aspect Preference Scale. Australian Psychologist, 16(2), 258-272.

Quarstein, V., McAfee, R., \& Glassman, M. (1992). The situational occurrence theory of job satisfaction. Human Relations, 45, 859-873. 
Robert, T., Young, J., \& Kelly, V. (2006). Relationships between adult worker's spiritual well-being and job satisfaction: a preliminary study. Counseling and Values, 50(3), 165.

Saane, N., Sluiter, J., Verbeek, J., \& Frings-Dresen, M. (2003). Reliability and validity of instruments measuring job satisfaction - a systematic review. Occupational Medicine, 53,191-200.

Seco, G. M. (2002). A satisfação dos professores. Teorias, modelos e evidências. Porto: Edições ASA.

Sebera, K. (2005). Leadership attributes and job satisfaction of school counsellors. Dissertation Presented to The Faculty of the College of Education of Ohio University. Consultado em Abril 2009, http://oak.cats.ohiou.edu/ ds688887/4.2.05.doc.

Simões, A., Ferreira, J., Lima, M., Pinheiro, M., Vieira, C., Matos, A., \& Oliveira, A. (2000). O bem-estar subjectivo: Estado actual dos conhecimentos. Psicologia, Educação e Cultura, IV (2), 243-279.

Spector, P. (1997). Job Satisfaction: Application, Assessment, Causes, and Consequences. Thousand Oaks, CA: Sage Publications.

Thierry, H. (1998). Motivation and satisfaction, in P. Drenth (Ed.) Handbook of Work and Organizational Psychology. Hove: Psychology Press/Erlbaum.

Wanous, J., Reichers, A., \& Hudy, M. (1997). Overall Job Satisfaction: How good are single-item measures? Journal of Applied Psychology, 82(2), 247-252.

Weiss, D. J., Dawis, R. V., England, G. W., \& Lofquist, L. H. (1967). Manual for the Minnesota Satisfaction Questionnaire (Minnesota Studies in Vocational Rehabilitation: XXII). Minneapolis: University of Minnesota, Industrial Relations Center Work Adjustament Project.

\section{Minnesota Satisfaction Questionnaire - Short Form: étude sur l'adaptation et la validation dans la population portuguaise}

La satisfaction au travail est le concept le plus étudié en Psychologie Organisationnelle (Spector, 1997). Malgré tout, il existe peu d'études récentes sur ses instruments d'évaluation (Saane, Sluiter, Verbeek, \& Frings-Dresen, 2003).

Ce travail prétend ajouter une contribution à l'étude des caractéristiques psychométriques d'un instrument largement utilisé dans ce contexte, le Minnesota Satisfaction Questionnaire (MSO) - Short Form (Weiss, Dawis, England, \& Lofquist, 1967) et exercer son adaptation sur la population portugaise. 136 travailleurs ont collabores à cette étude

L'instrument a montré de bonnes propriétés psychométriques, avec une valeur élevée de la cohérence interne, stabilité adéquate et une satisfaisante validité convergente (résultant de la comparaison avec le Cuestionario de Satisfaccion S2O/23 de Meliá \& Peiró, 1989). L’analyse factorielle exploratoire a révélé une structure qui montre l'existence de deux facteurs de satisfaction au travail.

La discussion des résultats a mis en évidence la nécessité d'études supplémentaires sur cette question, tout en donnant des pistes pour de futures recherches.

MOTS-CLÉS: satisfaction au travail; Minnesota Satisfaction Questionnaire (MSQ) Short Form; caractéristiques psychométriques; analyse factorielle. 


\section{Minnesota Satisfaction Questionnaire - Short Form: adaptation and validation study to the Portuguese population}

Job satisfaction is the most studied variable in Organizational Psychology (Spector, 1997). However, only a few recent researches on its instruments are available (Saane, Sluiter, Verbeek, \& Frings-Dresen, 2003).

This research aims to add a contribution to the study of the psychometric qualities of a widely used instrument in this context, the Minnesota Satisfaction Questionnaire (MSO) - Short Form (Weiss, Dawis, England, \& Lofquist, 1967), adapting it to the Portuguese population.

In this sample (136 employees), the instrument showed adequate psychometric qualities, with a high values for internal consistency, adequate stability and satisfactory convergent validity (resulting from the correlation with the Cuestionario de Satisfaccion S2O/23; Meliá \& Peiró, 1989). The exploratory factorial analysis revealed a structure that suggests as expected the existence of two factors of job satisfaction. The discussion of the results pinpoints the need for more studies on this field and raised some suggestions for future research.

KEY-WORDS: job satisfaction; Minnesota Satisfaction Questionnaire - Short Form; psychometric qualities; factor analysis. 